\title{
EFEITO DO EXTRATO AQUOSO DE LEUCENA NA GERMINAÇÃO E NO DESENVOLVIMENTO DO MILHO'
}

\author{
HÉLIO TEIXEIRA PRATES ${ }^{2}$, JOSÉ MAURO VALENTE PAES ${ }^{3}$, NÁDJA DE MOURA PIRES ${ }^{4}$, \\ ISRAEL ALEXANDRE PEREIRA FILHO ${ }^{5}$ e PAULO CÉSAR MAGALHÃES ${ }^{6}$
}

\begin{abstract}
RESUMO - Foram desenvolvidos bioensaios, na Embrapa-Centro Nacional de Pesquisa de Milho e Sorgo (CNPMS), para avaliar o efeito de extratos aquosos, a frio e a quente, da parte aérea de leucena (Leucaena leucocephala (Lam.) De Wit.), sobre a germinação e o desenvolvimento das plantas de milho (Zea mays L.). Os extratos foram preparados na concentração $20 \%$ (p/v), e avaliados em solo e papelgermiteste, em casa de vegetação, e em papel-filtro em laboratório. O extrato obtido com água fria (EF) e aplicado ao solo não causou nenhum efeito fitotóxico sobre a germinação e o desenvolvimento das plantas de milho. O extrato obtido com água quente (EQ), quando aplicado em papel-germiteste ou papel-filtro, causou redução no comprimento da raiz seminal, mas não interferiu na germinação das sementes de milho. O comprimento da raiz seminal foi um indicador mais sensível aos efeitos do EQ do que a germinação.
\end{abstract}

Termos para indexação: extrato da planta, germinação de sementes, comprimento da raiz, alelopatia.

\section{EFFECT OF AQUEOUS EXTRACT OF LEUCAENA ON GERMINATION AND GROWTH OF CORN}

\begin{abstract}
Bioassays were carried out at Embrapa-Centro Nacional de Pesquisa de Milho e Sorgo (CNPMS), to evaluate the effect of leucaena (Leucaena leucocephala (Lam.) De Wit.) cold and hot aqueous extracts on germination and growth of corn (Zea mays L.). Extracts at 20\% (w/v) concentration were used in greenhouse on soil and germitest paper, and on filter paper under laboratory conditions. Results indicated that extract obtained with cold water (EC) when applied in soil had no phytotoxic effect on germination and plant growth. Extraction with hot water $(\mathrm{EH})$ caused reduction in root length, but had no effect on maize seeds germination. The root length was more efficient as a sensitive indicator to EH than germination.
\end{abstract}

Index terms: plant extract, seed germination, root length, allelopathy.

\section{INTRODUÇÃO}

A leucena (Leucaena leucocephala (Lam.) De Wit.) é uma leguminosa originária do México, e é encontrada em toda região tropical (Skerman, 1977).

${ }^{1}$ Aceito para publicação em 30 de junho de 1999.

${ }^{2}$ Químico, D.Sc., Embrapa-Centro Nacional de Pesquisa de Milho e Sorgo (CNPMS), Caixa Postal 151, CEP 35701-970 Sete Lagoas, MG. E-mail: htprates@cnpms.embrapa.br

${ }^{3}$ Eng. Agrôn., D.Sc., Epamig/CTTP, Caixa Postal 351, CEP 38001-970 Uberaba, MG

${ }^{4}$ Eng. Agrôn., D.Sc., Caixa Postal 151, CEP 35701-970 Sete Lagoas, MG. Bolsista da FAPEMIG.

${ }^{5}$ Eng. Agrôn., M.Sc., Embrapa-CNPMS

${ }^{6}$ Eng. Agrôn., Ph.D., Embrapa-CNPMS
Essa planta apresenta, atualmente, múltipla utilização, com destaque para o reflorestamento de áreas degradadas, alimentação animal, adubação verde e também para o efeito alelopático.

Budelman (1988) observou que a cobertura do solo com leucena apresenta propriedades de controle de plantas daninhas, e que esse efeito ocorre em razão da presença de aleloquímicos na planta. A leucena contém em seus tecidos um aminoácido nãoprotéico, o ácido $\beta$-[N-(3-hidroxi-4-oxopiridil)]- $\alpha$ aminopropiônico (mimosina), muito tóxico para animais (Smith \& Fowden, 1966). No entanto, enzimas presentes na planta podem degradar (autólise) rapidamente a mimosina para 3,4-diidroxipiridona (DHP), piruvato e amônia (Smith \& Fowden, 1966; Megarrity, 1978; Lowry et al., 1983, 1985; Wee \& 
Wang, 1987; Adeneye, 1991). Lowry et al. (1983) observaram que a ação dessas enzimas é mais rápida à temperatura de $30^{\circ} \mathrm{C}$, pois metade da mimosina contida no macerado de folhas foi degradada em sete minutos e virtualmente completada em 30 minutos. Entretanto, à temperatura acima de $75^{\circ} \mathrm{C}$, o conteúdo de mimosina praticamente não foi afetado em virtude da inativação das enzimas responsáveis pela sua degradação.

$\mathrm{Na}$ literatura existem vários registros sobre a toxicidade da mimosina em plantas (Chou, 1986; Tawata \& Hongo, 1987). Foi observado por Smith \& Fowden (1966) que mimosina e DHP inibiram o crescimento de seedlings de feijão-mungo (Phaseolus aureus). Kuo et al. (1982) mostraram que a mimosina e extratos aquosos de folhas de leucena inibiram o crescimento da radícula de alface (Lactuca sativa) e arroz (Oryza sativa). Estes autores afirmam, ainda, que a mimosina é responsável pelo efeito alelopático da leucena.

Tawata \& Hongo (1987) relatam que o crescimento de radícula de arroz (Oryza sativa), rabanete (Raphanus sativus), mostarda (Brassica rapa) e feijão (Phaseolus vulgaris) foi estimulado pela mimosina a uma concentração igual ou menor que $1 \mu \mathrm{g} \mathrm{mL}{ }^{-1}$. Entretanto, em cenoura (Daucus carota) e picão-preto (Bidens pilosa), o crescimento da radícula foi inibido pela mimosina a uma concentração igual ou menor que $10 \mu \mathrm{g} \mathrm{mL}^{-1}$; à concentração de $100 \mu \mathrm{g} \mathrm{mL}^{-1}$ a mimosina inibiu completamente o crescimento do sistema radicular dessas espécies.

Estudos realizados por Souza Filho et al. (1997) com o extrato aquoso da parte aérea da leucena mostraram que houve inibição da germinação e do comprimento da radícula de desmódio (Desmodium adscendens), guanxuma (Sida rhombifolia) e assa-peixe (Vernonia polyanthes), e concluíram que esses efeitos provavelmente estariam relacionados com a mimosina.

Portanto, há necessidade de investigar as interações planta, solo e cultura para otimizar o uso dessa leguminosa no agroecossistema.

O objetivo deste estudo foi investigar o efeito fitotóxico dos extratos aquosos da parte aérea da leucena, na germinação e desenvolvimento da planta de milho em condições de casa de vegetação e laboratório.

\section{MATERIAL E MÉTODOS}

\section{Bioensaio em casa de vegetação}

Dois bioensaios foram conduzidos em condições de casa de vegetação, na Embrapa-Centro Nacional de Pesquisa de Milho e Sorgo (CNPMS), Sete Lagoas, MG. No primeiro bioensaio o delineamento experimental constituiu-se em quatro tratamentos, dispostos em blocos casualizados, com quatro repetições. Em cada tratamento utilizou-se vaso de plástico com capacidade de $3 \mathrm{~L}$, contendo Latossolo Vermelho-Escuro, fase terraço, distrófico, textura argilosa, coletado na camada de $0-20 \mathrm{~cm}$. Baseado nas características químicas: $\mathrm{pH}$ em $\mathrm{H}_{2} \mathrm{O}, 5,7 ; \mathrm{P}, 8 \mathrm{mg} \mathrm{dm}^{-3} ; \mathrm{K}, 139 \mathrm{mg} \mathrm{dm}^{-3}$; $\mathrm{Ca}, 2,88 \mathrm{cmol}_{\mathrm{c}} \mathrm{dm}^{-3} ; \mathrm{Mg}, 0,65 \mathrm{cmol}_{\mathrm{c}} \mathrm{dm}^{-3}$ e $\mathrm{Al}$, $0,5 \mathrm{cmol}_{\mathrm{c}} \mathrm{dm}^{-3}$, este solo foi adubado com $100 \mathrm{mg} \mathrm{kg}^{-1}$ de $\left.\mathrm{N}\left(\left(\mathrm{NH}_{4}\right)_{2} \mathrm{SO}_{4}\right)\right) ; 120 \mathrm{mg} \mathrm{kg}^{-1}$ de $\mathrm{P}\left(\mathrm{KH}_{2} \mathrm{PO}_{4}\right)$; $100 \mathrm{mg} \mathrm{kg}^{-1}$ de $\mathrm{K}\left(\mathrm{K}_{2} \mathrm{SO}_{4}\right) ; 10 \mathrm{mg} \mathrm{kg}^{-1}$ de $\mathrm{Zn}$ $\left(\mathrm{Zn} \mathrm{SO}_{4} .7 \mathrm{H}_{2} \mathrm{O}\right) ; 5 \mathrm{mg} \mathrm{kg}^{-1}$ de $\mathrm{Mn}\left(\mathrm{MnCl}_{2}\right) ; 2 \mathrm{mg} \mathrm{kg}^{-1} \mathrm{de}$ $\mathrm{Cu}\left(\mathrm{CuSO}_{4}\right)$ e $0,5 \mathrm{mg} \mathrm{kg}^{-1}$ de $\mathrm{B}\left(\mathrm{H}_{3} \mathrm{BO}_{3}\right)$. Os fertilizantes foram incorporados ao solo utilizando-se um misturador mecânico.

Em cada vaso foram aplicados $250 \mathrm{~mL}$ de extrato aquoso obtido com água à temperatura ambiente (EF). O EF foi obtido utilizando-se $200 \mathrm{~g}$ de folhas frescas de leucena, maceradas em 1 litro de água destilada $(20 \%$ p/v), em liquidificador industrial. $\mathrm{O}$ macerado foi passado por uma peneira com malha de $2 \mathrm{~mm}$. O filtrado foi centrifugado a uma rotação de $3.000 \mathrm{rpm}$ durante três minutos, coletando-se em seguida o líquido sobrenadante, que apresentou $\mathrm{pH} 7,0$. O EF foi utilizado concentrado (100\%) e diluído com água destilada nas concentrações de $80 \%$ e $40 \%$, empregando-se água como testemunha.

Após o ajuste da umidade, em torno de $80 \%$ da capacidade campo, plantaram-se quatro sementes por vaso do milho híbrido triplo BR 3123. Posteriormente, obteve-se o peso inicial de cada vaso. A aplicação dos extratos a diferentes concentrações foi feita diariamente, baseando-se na perda de umidade dos vasos. Esgotados os extratos, a reposição foi feita somente com água.

Decorridos 30 dias após o plantio, avaliaram-se altura de plantas (AP), em $\mathrm{cm}$, peso da matéria seca de folhas (PMSF), em g, peso da matéria seca de raízes (PMSR), em g, e peso da matéria seca total (PMST), em g.

No segundo bioensaio, o extrato foi obtido triturandose $100 \mathrm{~g}$ de folhas de leucena, em liquidificador industrial. O triturado foi colocado em percolador de vidro, conforme descrito por Tang \& Young (1982), com modificações. Em seguida, foram adicionados $500 \mathrm{~mL}$ de água destilada a $80^{\circ} \mathrm{C}$, conforme metodologia descrita por Lowry et al. (1983). Após 1 minuto de infusão, coletou-se o extrato 
aquoso à temperatura de $65^{\circ} \mathrm{C}$ e $\mathrm{pH} 7,0 . \mathrm{O}$ extrato obtido com água à temperatura de $80^{\circ} \mathrm{C}(\mathrm{EQ})$ foi resfriado e armazenado em geladeira a $10^{\circ} \mathrm{C}$

O EQ foi avaliado em papel-germiteste. O papel foi umedecido com água destilada, colocando-se ao longo do menor comprimento da folha dez sementes do milho híbrido triplo BR 3123, cobrindo-se no final com duas folhas. Em seguida, essas folhas foram enroladas em forma de cilindro, colocando-se dois rolos em proveta de $1.000 \mathrm{~mL}$. Em cada proveta foram adicionadas $700 \mathrm{~mL}$ do EQ, concentrado $(20 \%$ p/v) e diluído com água destilada nas concentrações 50, 25 e 12,5\%, utilizando-se água como testemunha. Os tratamentos foram dispostos em delineamento inteiramente ao acaso, com quatro repetições. Cada proveta foi coberta com papel-alumínio, para evitar a entrada de luz e inibir o desenvolvimento de algas. Logo após, foi instalado o sistema de aeração das provetas, as quais foram cobertas com saco de plástico, sendo retirado no início da emergência das plântulas de milho. As soluções foram trocadas a cada 48 horas, para reduzir o efeito de fermentação. Decorridos oito dias, foi avaliada a porcentagem de sementes germinadas e o comprimento da raiz seminal $(\mathrm{CRS}), \mathrm{em} \mathrm{cm}$.

\section{Bioensaio em laboratório}

$\mathrm{O}$ extrato utilizado neste bioensaio foi preparado à semelhança do empregado em casa de vegetação. Em cada gerbox foram adicionados $10 \mathrm{~mL}$ do $\mathrm{EQ}$, concentrado ( $20 \%$ p/v) e diluído com água destilada nas concentrações 90, 80, 70, 60, 50, 40, 30, 20, e 10\%, utilizando-se água como testemunha. Os tratamentos foram dispostos em delineamento inteiramente casualizado, com quatro repetições.

O bioensaio foi realizado em germinador tipo Seedburo, regulado para temperatura alternada de $30^{\circ} \mathrm{C}$ com oito horas-luz e $20^{\circ} \mathrm{C}$ com 16 horas sem luz. O teste foi realizado em caixas gerbox transparentes, forradas com três folhas de papel-filtro, previamente autoclavadas a $120^{\circ} \mathrm{C}$ por uma hora. Em cada gerbox, foram colocadas seis sementes, previamente desinfetadas com solução de hipoclorito de sódio a $2 \%$.

Após um período de seis dias, avaliaram-se porcentagem de sementes germinadas, comprimento da parte aérea, comprimento da raiz primária e das raízes secundárias, número de raízes secundárias e biomassa seca da parte aérea e das raízes. Os valores obtidos foram submetidos à análise de variância, sendo os valores de comprimento e biomassa analisados por regressão, e os dados de porcentagem de germinação e número de raízes secundárias, comparados pelo teste Tukey a $5 \%$ de probabilidade.

\section{RESULTADOS E DISCUSSÃO}

\section{Bioensaio em casa de vegetação}

A análise estatística dos dados mostrados na Tabela 1 não indicou diferença significativa na altura de plantas (AP), peso da matéria seca de folhas (PMSF), peso da matéria seca de raízes (PMSR) e peso da matéria seca total (PMST) quando se utilizaram diferentes concentrações de extrato (EF) de leucena. Esperava-se inibição do crescimento e desenvolvimento do milho causado pelo efeito tóxico da mimosina em plantas, conforme observações de vários autores (Smith \& Fowden, 1966; Megarrity, 1978; Lowry et al., 1983, 1985; Wee \& Wang, 1987; Adeneye, 1991). Entretanto, observou-se estímulo no desenvolvimento do milho, no tratamento em que se utilizou o EF concentrado (100\%) (Tabela 1). Tukey Junior (1969) afirma que nem todas as substâncias liberadas pelas plantas são inibidoras, e podem, ao contrário, ser estimulantes, citando como exemplo os nutrientes minerais, aminoácidos e ácidos orgânicos, carboidratos e reguladores de crescimento. Segundo Kluthcouski (1982), a leucena aumentou a matéria orgânica do solo e a disponibilidade de nitrogênio, nutriente essencial para o crescimento e desenvolvimento das culturas.

Outro aspecto a ser considerado é que a atividade da mimosina no solo pode ser transitória, estando sujeita à adsorção pelos colóides, à degradação, à inativação e à transformação por microrganismos. Segundo Putnam \& Duke (1978), as substâncias aleloquímicas necessitam estar em uma concentração mínima no meio ambiente, para atuarem sobre os organismos.

Observa-se, na Fig.1, redução significativa do comprimento da raiz seminal (CRS), em face da concentração do extrato (EQ) de leucena. Verifica-se que uma concentração menor que $12,5 \%$ causou uma redução de $50 \%$ no comprimento da raiz. Nas concentrações maiores de EQ, o efeito foi mais severo sobre o comprimento da raiz das plantas de milho. Verificou-se ainda que as diferentes concentrações do extrato causaram necrose no ápice da raiz seminal. Entretanto, as diferentes concentrações do extrato não mostraram efeito na germinação das sementes de milho, pelo teste de Tukey a $5 \%$ de probabilidade (Fig. 2), e no comprimento da parte aérea das plântulas. 
TABELA 1. Valores médios de altura de plantas (AP), peso da matéria seca de folhas (PMSF), peso da matéria seca de raízes (PMSR) e peso da matéria seca total (PMST), de plantas de milho tratadas com diferentes concentrações do extrato aquoso (EF) de leucena. Embrapa-CNPMS, Sete Lagoas, MG, 19981.

\begin{tabular}{clccc}
\hline EF $(\%)$ & AP $(\mathrm{cm})$ & PMSF $(\mathrm{g})$ & PMSR $(\mathrm{g})$ & PMST $(\mathrm{g})$ \\
\hline 0 & $61,75 \mathrm{a}$ & $3,54 \mathrm{a}$ & $2,50 \mathrm{a}$ & $6,04 \mathrm{a}$ \\
40 & $66,75 \mathrm{a}$ & $4,06 \mathrm{a}$ & $2,62 \mathrm{a}$ & $6,68 \mathrm{a}$ \\
80 & $60,78 \mathrm{a}$ & $3,03 \mathrm{a}$ & $1,87 \mathrm{a}$ & $4,90 \mathrm{a}$ \\
100 & $71,25 \mathrm{a}$ & $4,51 \mathrm{a}$ & $2,89 \mathrm{a}$ & $7,40 \mathrm{a}$ \\
\hline C.V. $(\%)$ & 10,83 & 20,89 & 20,05 & 18,75 \\
\hline
\end{tabular}

Médias, nas colunas, seguidas de mesma letra não diferem entre si pelo teste de Tukey, a 5\% de probabilidade.

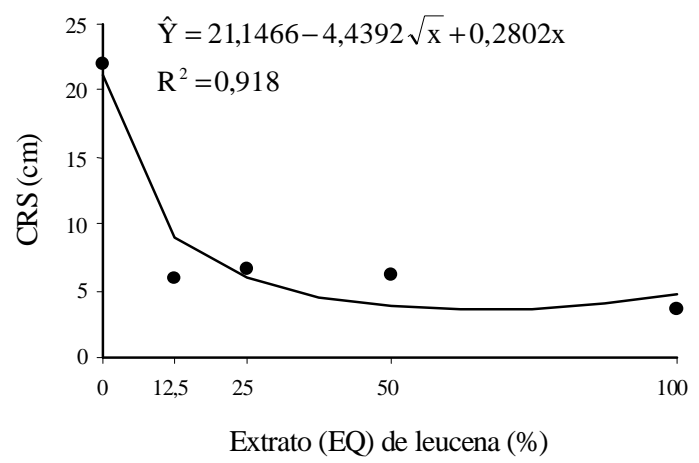

FIG. 1. Comprimento da raiz seminal (CRS) das plântulas de milho em razão de diferentes concentrações de extrato (EQ) de leucena. Embrapa-CNPMS, Sete Lagoas, MG, 1998.

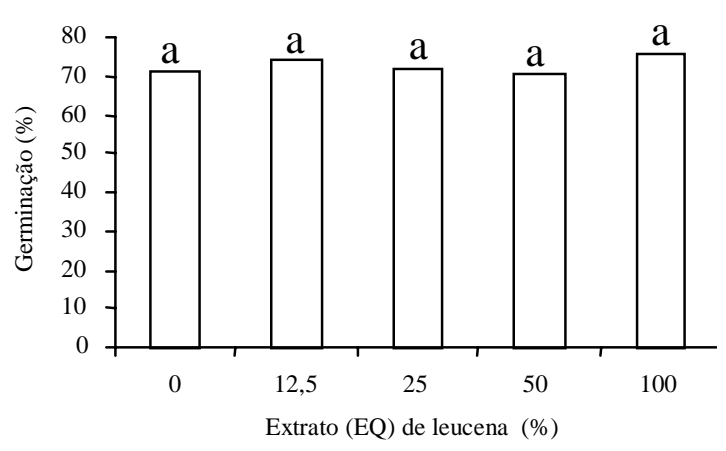

FIG. 2. Porcentagem de germinação de milho em razão de diferentes concentrações de extrato (EQ) de leucena. Embrapa-CNPMS, Sete Lagoas, MG, 1998.
Os extratos aquosos utilizados nos dois experimentos apresentaram $\mathrm{pH} 7,0$. Esse valor de $\mathrm{pH}$ não influenciou a germinação e o desenvolvimento da radícula, confirmando observações descritas na literatura (Rao \& Reddy, 1981; Eberlein, 1987; Pattnaik \& Misra, 1987), em que os efeitos depressivos são manifestados apenas a valores de $\mathrm{pH}$ igual ou inferior a 3,0 ou igual ou superior a 9,0 .

\section{Bioensaio em laboratório}

O extrato (EQ) da leucena não inibiu a germinação e o surgimento de raízes secundárias do milho. Entretanto, o comprimento e a biomassa seca da parte aérea, das raízes e total das plântulas de milho foram inibidos pelo extrato, em função da sua concentração (Fig. 3). Nas concentrações mais altas, foi
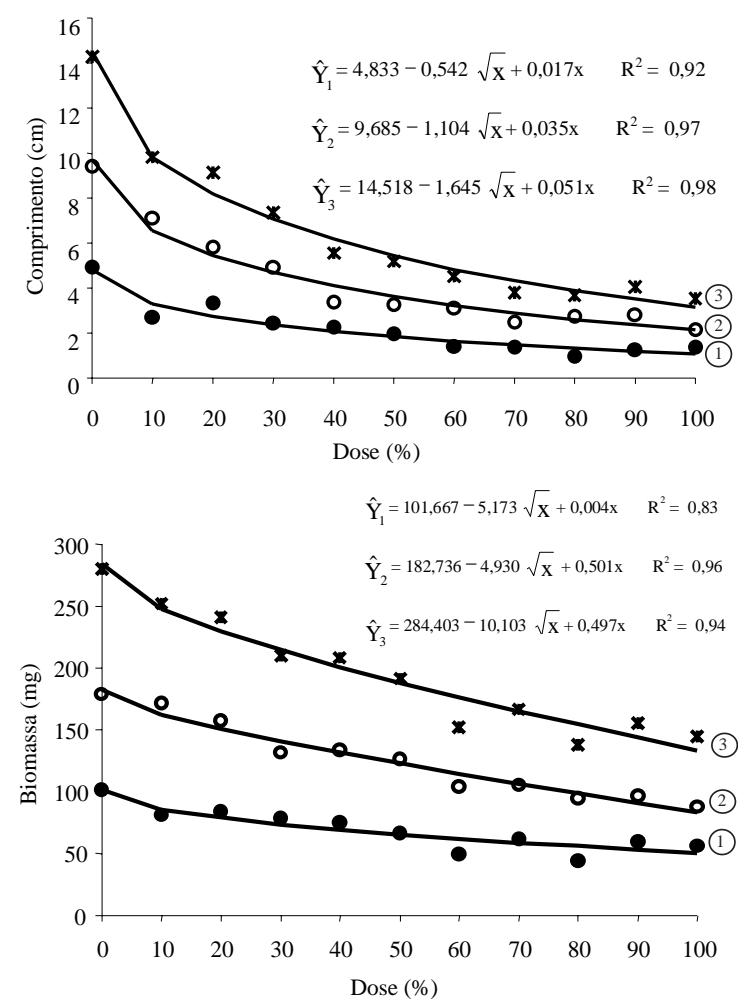

FIG.3. Comprimento e biomassa seca da parte aérea (1), raízes (2) e total (3) de plântulas de milho, após seis dias de semeadura em papel-filtro, em razão de diferentes concentrações de extrato de leucena. Embrapa-CNPMS, Sete Lagoas, MG, 1998. 
observado que as raízes secundárias apresentavam coloração avermelhada e necrose apical, principalmente na raiz primária. Resultados semelhantes são descritos na literatura por Bhowmik \& Doll (1982) e Jacobi \& Ferreira (1991).

A avaliação do comprimento de radícula mostrouse semelhante ao observado no bioensaio realizado em casa de vegetação. Tal inibição no crescimento da radícula se deve provavelmente à mimosina presente na parte aérea da leucena. Os resultados estão de acordo com Souza Filho et al. (1997), que mostraram que a parte aérea da leucena inibiu o desenvolvimento de algumas plantas daninhas de pastagens.

\section{CONCLUSÕES}

1. O extrato aquoso de leucena, obtido com água à temperatura ambiente $(\mathrm{EF})$, quando aplicado ao solo não causa problema de fitotoxicidade para as plantas de milho.

2. A ausência de fitotoxicidade, observada na planta de milho quando aplica-se EF ao solo, viabiliza o uso da leucena como potencial herbicida de origem vegetal.

3. O extrato aquoso obtido com água quente (EQ), quando aplicado em papel-germiteste provoca efeito sobre o crescimento da raiz seminal, mas não causa efeito sobre a parte aérea das plantas de milho.

4. No bioensaio em gerbox, com sementes de milho, tanto o comprimento da radícula como da parte aérea são sensíveis ao extrato EQ.

\section{REFERÊNCIAS}

ADENEYE, J.A. Mimosine content in various fractions of Leucaena leucocephala grown in western Nigeria. Animal Feed Science and Technology, Amsterdam, v.33, p.349-353, 1991.

BHOWMIK, P.C.; DOLL, J.D. Corn and soybean response to allelopathic effects of weed and corp residue. Agronomy Journal, Madison, v.74, p.601606, 1982.
BUDELMAN, A. The performance of the leaf mulches of Leucaena leucocephala, Flemingia macrophyll and Gliricidia sepium in weed control. Agroforestry Systems, Dordrecht, v.6, p.137-145, 1988.

CHOU, C.H. The role of allelopathy in subtropical agroecosystem in Taiwan. In: PUTNAM, A.R.; TANG, C.S. (Eds.). The science of allelopathy. New York : J. Wiley, 1986. p.57-73.

EBERLEIN, C.V. Germination of Sorghum almun seeds and longevity in soil. Weed Science, Champaign, v.35, p.796-801, 1987.

JACOBI, U.S.; FERREIRA, A.G. Efeitos alelopáticos de Mimosa bimucronata (DC) OK. sobre espécies cultivadas. Pesquisa Agropecuária Brasileira, Brasília, v.26, n.7, p.935-943, jul. 1991.

KLUTHCOUSKI, J. Leucaena: alternativa para pequena e média agricultura. Goiânia : Embrapa-CNPAF, 1982. 12p. (Embrapa-CNPAF. Circular Técnica, 6).

KUO, Y.L.; CHOU, C.H.; HU, T.W. Allelopathic potencial of Leucaena leucocephala. Leucaena Research Report, Taipei, v.3, p.65-70, 1982.

LOWRY, J.B.; TANGENDADJAJA, M.; COOK, N.W. Measurement of mimosine and metabolites in biological materials. Journal of the Science of Food and Agriculture, Barking, v.36, p.799-807, 1985.

LOWRY, J.B.; TANGENDADJAJA, M.; TANGENDADJAJA, B. Autolysis of mimosine to 3-hydroxy-4-1(H)pyridone in green tissues of Leucaena leucocephala. Journal of the Science of Food and Agriculture, Barking, v.34, p.529-533, 1983.

MEGARRITY, R.G. An automed colorimetric method for mimosine in Leucaena leaves. Journal of the Science of Food and Agriculture, Barking, v.29, p.182-186, 1978.

PATTNAIK, S.K.; MISRA, N.K. Morphology and germination characteristics of Aristida seeds. Acta Botanica Hungarica, Budapest, v.33, n.3/4, p.413420, 1987.

PUTNAM, A.R.; DUKE, W.D. Allelopathy in agroecossystems. Annual Review of Phytopathology, Palo Alto, v.16, p.431-451, 1978.

RAO, P.N.; REDDY, B.V.N. Autoecological studies in Indigofera linifolia (L.f.) Retz. I. Germination behaviour of the seeds. Journal of the Indian Botanical Society, Madras, v.60, n.1, p.51-57, 1981 
SKERMAN, P.J. Tropical forage legumes. Rome : FAO, 1977. 609p.

SMITH, I.K.; FOWDEN, L. A study of mimosine toxicity in plants. Journal of Experimental Botany, Oxford, v.17, p.750-761, 1966.

SOUZA FILHO, A.P.; RODRIGUES, R.A.; RODRIGUES, T.J.D. Efeitos do potencial alelopático de três leguminosas forrageiras sobre três invasoras de pastagens. Pesquisa Agropecuária Brasileira, Brasília, v.32, n.2, p.165-170, fev. 1997.

TANG, C.H.; YOUNG, C.C. Collection and identification of allelopathic compounds from the undisturbed root system of bigalta limpograss (Hermarthria altissima). Plant Physiology, Rockville, v.68, n.1, p.155-160, 1982.

TAWATA, S.; HONGO, F. Mimosine allelophathy of Leucaena. Leucaena Research Reports, Taipei, v.8, p.40-41, 1987.

TUKEY JUNIOR, H.B. Implications of allelopathy in agricultural plant science. Botanical Review, Bronx, v.35, p.1-16, 1969.

WEE, K. L.; WANG, S.S. Effect of post-harvest on the degradation of mimosine in Leucaena leucocephala leaves. Journal of the Science of Food and Agriculture, Barking, v.39, p.195-201, 1987. 